\title{
Pemetaan Tingkat Kebisingan di Rumah Sakit Islam A. Yani Surabaya
}

\author{
Mirza Arianti Savitri dan Arie Dipareza Syafei \\ Departemen Teknik Lingkungan, Fakultas Teknik Sipil, Lingkungan, dan Kebumian Institut Teknologi \\ Sepuluh Nopember (ITS) \\ e-mail:dipareza@enviro.its.ac.id
}

\begin{abstract}
Abstrak-Kendaraan bermotor seperti bus, mobil, sepeda motor, truk ringan sampai truk berat merupakan sumber kebisingan utama dijalan raya. Kebisingan adalah suara yang tidak dikehendaki dan suara ini sangat mengganggu manusia, dalam beberapa kasus dapat menimbulkan gangguan pendengaran ataupun terjadinya kecelakaan lalulintas. Pada penelitian untuk menentukan nilai tingkat kebisingan, dilakukan tahapan yaitu menghitung nilai LTMS, menghitung nilai LS, menghitung nilai LM, kemudian menghitung nilai LSM. Pengambilan sampling dilakukan selama 7 hari. Dilakukan juga pemetaan kebisingan menggunakan software surfer. Hasil penelitian menunjukkan bahwa nilai kebisingan pada hari Senin hingga hari Minggu, melebihi baku mutu. Pada hari Senin, nilai tingkat kebisingan berkisar antara 63-72 dBA. Pada hari Selasa nilai kebisingan berkisar antara 64-74 dBA. Untuk hari Rabu nilai kebisingan berkisar antara 64-73 dBA, hari Kamis nilai kebisingan berkisar antara 59-72 dBA. Pada hari Jumat nilai kebisingan berkisar antara 58-74 dBA. Pada hari Sabtu nilai kebisingan berkisar antara 60-74 dBA dan hari Minggu nilai kebisingan berkisar antara 67-71 dBA.
\end{abstract}

Kata Kunci-Kebisingan, Kendaraan Bermotor, Pemetaan, Surfer.

\section{PENDAHULUAN}

$\mathrm{K}$ EGIATAN transportasi tidak lepas dari adanya kendaraan bermotor [1]. Dewasa ini nilai kepemilikan kendaraan bermotor semakin meningkat, baik kendaraan bermotor milik pribadi maupun yang bukan milik pribadi seperti angkutan umum [2]. Hal tersebut menyebabkan semakin meningkatnya kepadatan arus lalu lintas di jalan raya, dan hal ini sangat erat hubungannya dengan kebisingan, karena kebisingan lalu lintas berasal dari suara yang dihasilkan dari kendaraan bermotor terutama dari mesin kendaraan, knalpot, serta akibat interaksi antara roda dengan jalan [3].

Fasilitas kesehatan masyarakat, salah satunya rumah sakit merupakan tempat yang dihuni oleh orang-orang yang terganggu kesehatannya dan yang membutuhkan konsentrasi tinggi, sehingga membutuhkan suasana yang tenang dan jauh dari kebisingan [4]. Pengaruh kebisingan terhadap manusia secara fisik tidak saja menganggu organ pendengaran, tetapi juga dapat menimbulkan gangguan pada organ-organ tubuh yang lain [5]. Pada umumnya masalah yang terkait dengan kebisingan adalah gangguan komunikasi [6]. Sedangkan pengaruh bising secara psikologis, yaitu berupa rasa tidak nyaman, kurang konsentrasi, dan susah tidur [7]. Ada beberapa kawasan dan lingkungan kegiatan yang ditentukan baku mutu kebisingannya. Untuk kawasan yaitu perumahan dan pemukiman, perdagangan dan jasa, perkantoran, ruang terbuka hijau, industri, pemerintahan dan fasilitas umum, rekreasi dan kawasan khusus (bandar udara, stasiun kereta api, pelabuhan laut dan cagar budaya). Dan lingkungan kegiatan meliputi rumah sakit atau sejenisnya, sekolah atau sejenisnya dan tempat ibadah atau sejenisnya [8].

Batas paparan kebisingan bagi rumah sakit yang diperbolehkan tidak lebih dari 40 desibel (dB) pada lingkungan rumah sakit, dan $35 \mathrm{~dB}$ pada bagian dalam ruang rawat inap [9]. Ruang-ruang lain di rumah sakit juga memiliki ambang batas bunyi yaitu dengan batas waktu pemaparan maksimal 8 jam, pembatasan pemaparan kebisingan ini diperlukan untuk memberikan kesempatan bagi pasien untuk beristirahat dalam proses penyembuhan.

\section{METODE PENELITIAN}

\section{A. Penentuan Lokasi dan Jumlah Titik Sampling}

Penentuan lokasi dan jumlah titik sampling ini dilakukan pada seluruh area rumah sakit dan pada area-area tertentu [10]. Pada penentuan lokasi dan jumlah titik sampling nantinya akan dilakukan pengambilan sampel/data untuk menentukan nilai tingkat kebisingan [11]. Pengambilan data dilakukan selama 7 hari, karena selama 7 hari sudah dapat menentukan nilai tingkat kebisingan dan tidak perlu mengulang hari yang sama sampai dua atau tiga kali bahkan lebih [12].

\section{B. Penentuan Waktu Pengukuran}

Penentuan waktu pengukuran dilakukan setiap hari dimulai pukul 6 pagi hingga pukul 6 pagi selama satu minggu. Untuk Pengambilan sampel dilakukan selama 10 menit untuk setiap pengukuran dan pembacaan dilakukan setiap 5 detik dengan pengambilan data pada waktu level siang hari (Ls) dan pada waktu level malam hari (Lm). Penentuan waktu sampling berdasarkan pada jam-jam kepadatan lalu lintas [13].

\section{Penentuan Vegetasi Sebagai Barier Buatan}

Penentuan vegetasi ini bertujuan untuk mereduksi nilai kebisingan. Kebisingan dapat diatasi atau direduksi dengan ditambahkannya barier atau penghalang buatan pada lokasi yang memiliki nilai kebisingan yang tinggi. Secara umum, penghalang dengan tanaman diterapkan apabila tidak diperlukan penurunan kebisingan yang terlalu besar atau dikombinasikan dengan penghalang lain apabila dibutuhkan tingkat efektivitas pengurangan kebisingan yang besar [14]. 


\section{Plotting / Pemetaan}

Pemetaan yaitu penggambaran secara visual yang menghasilkan sebuah peta, sedangkan pemetaan kebisingan berarti penggambaran secara visual dari tingkat kebisingan yang ditimbulkan pada tiap-tiap titik pengamatan dimana pengukuran ini akan menghasilkan sebuah peta kontur kebisingan. Penelitian ini bertujuan untuk menentukan distribusi tingkat kebisingan pada suatu area.

\section{HASIL DAN PEMBAHASAN}

\section{A. Penentuan Lokasi dan Jumlah Titik Sampling}

Penentuan lokasi dan jumlah titik sampling ditentukan secara random. Metode tersebut digunakan karena diasumsikan bahwa akan ada perbedaan tingkat kebisingan pada masing-masing titik sampling berdasarkan jarak titik sampling dengan sumber kebisingan dan juga agar pada saat dilakukan pemetaan nilai kebisingan tersebut dengan software, hasil konturnya akan terlihat lebih spesifik. Untuk lebih jelasnya dapat diliat pada Gambar 1 berikut ini.

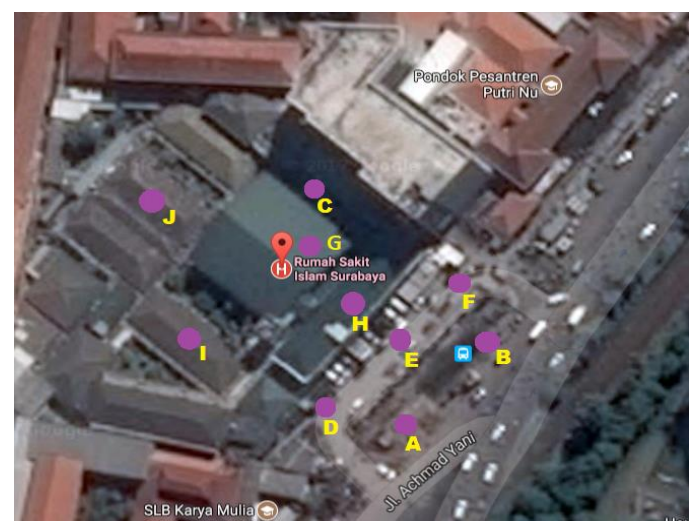

Gambar 1. Hasil kontur pemetaan bangunan

Keterangan: A: Tempat Parkir

B: Tempat Parkir

C: Lorong Poli

D: Di sekitar tempat parkir mobil ambulance

E: Di samping pintu lobby

F: Di samping Instalasi Gawat Darurat

G: Di depan Ruang Bersalin

H: Di depan Instalasi Gawat Darurat bagian dalam rumah sakit

I: Rawat Inap

J: Rawat Inap

\section{B. Penentuan Waktu Pengukuran}

Untuk waktu pengukuran dilakukan mulai hari Senin hingga hari Minggu selama 1 minggu pada pukul 6 pagi hingga 6 pagi. Pengambilan sampel dilakukan selama 10 menit untuk setiap pengukuran dan pembacaan dilakukan setiap 5 detik dengan pengambilan data pada waktu level siang hari (Ls) dan pada waktu level malam hari (Lm). Penentuan waktu sampling berdasarkan pada jam-jam kepadatan lalu lintas. Berikut rentang waktu pengukurannya:

a) $L 1$ diambil pada jam 08.00 mewakili jam $06.00-09.00$

b) $L 2$ diambil pada jam 10.00 mewakili jam $09.00-14.00$

c) $L 3$ diambil pada jam 16.00 mewakili jam $14.00-17.00$

d) $L 4$ diambil pada jam 18.00 mewakili jam $17.00-22.00$ e) $L 5$ diambil pada jam 24.00 mewakili jam $22.00-24.00$

f) $L 6$ diambil pada jam 02.00 mewakili jam $24.00-03.00$

g) $L 7$ diambil pada jam 04.00 mewakili jam $03.00-06.00$

Pengukuran tingkat kebisingan dilakukan dengan menggunakan Sound Level Meter (SLM) di Rumah Sakit Islam A. Yani Surabaya dengan jumlah titik sampling yang telah ditentukan sebelumnya. Setelah data terkumpul, selanjutnya data diolah dan dihitung menggunakan rumus LTMS, LS, LM dan LSM. Berikut rumus-rumus yang digunakan:

$$
\begin{aligned}
& \text { 1) } \mathrm{LTMS}=10 \log 1 / 600\left\{5.10^{0,1 \mathrm{~L} 1}+5.10^{0,1 \mathrm{~L} 2}+\ldots .+5.10^{0,1}\right. \\
& \left.{ }^{\mathrm{L} 120}\right\} \mathrm{dB}(\mathrm{A}) \\
& \text { 2) } \mathrm{LS}=10 \log 1 / 16\left(\mathrm{~T} 1.10^{0,1 \mathrm{~L} 5}+\ldots .+\mathrm{T} 4.10^{0,1 \mathrm{~L} 5}\right) \mathrm{dB}(\mathrm{A}) \\
& \text { 3) } \mathrm{LM}=10 \log 1 / 8\left(\mathrm{~T} 5.10^{0,1 \mathrm{~L} 5}+\ldots .+\mathrm{T} 7 \cdot 10^{0,1 \mathrm{~L} 7}\right) \mathrm{dB}(\mathrm{A}) \\
& \text { 4) } \mathrm{LSM}=10 \log 1 / 24\left(16.10^{0,1 \mathrm{~L} 5}+8.10^{0,1 \mathrm{~L} 5}\right) \mathrm{dB}(\mathrm{A})
\end{aligned}
$$

Setelah data dihitung menggunakan rumus-rumus tersebut, kemudian dihasilkan data-data LSM yang nantinya akan

\begin{tabular}{|c|c|c|c|c|c|c|c|c|c|}
\hline \multirow{3}{*}{ Lokasi } & \multicolumn{7}{|c|}{ Hari } & \multirow{3}{*}{$\begin{array}{l}\text { Baku } \\
\text { Mutu }\end{array}$} & \multirow{3}{*}{ Keterangan } \\
\hline & \multirow{2}{*}{$\begin{array}{c}\text { senin } \\
\text { (Lsm) } \\
\text { dBA } \\
\end{array}$} & \multirow{2}{*}{$\begin{array}{l}\text { selasa } \\
\begin{array}{l}\text { (Lsm) } \\
\text { dBA }\end{array} \\
\end{array}$} & \multirow{2}{*}{$\begin{array}{c}\text { rabu } \\
\text { (Lsm) } \\
\text { dBA }\end{array}$} & \multirow{2}{*}{$\begin{array}{c}\text { kamis } \\
(\mathrm{Lsm}) \\
\mathrm{dBA}\end{array}$} & \multirow{2}{*}{$\begin{array}{c}\text { jumat } \\
\text { (Lsm) } \\
\text { dBA } \\
\end{array}$} & \multirow{2}{*}{$\begin{array}{l}\text { sabtu } \\
\text { (Lsm) } \\
\text { dBA }\end{array}$} & \multirow{2}{*}{$\begin{array}{c}\text { minggu } \\
(\mathrm{Lsm}) \\
\mathrm{dBA} \\
\end{array}$} & & \\
\hline & & & & & & & & & \\
\hline $\mathrm{A}$ & 71 & 73 & 72 & 72 & 72 & 73 & 71 & 55 & TS \\
\hline B & 72 & 74 & 71 & 66 & 74 & 75 & 73 & 55 & TS \\
\hline $\mathrm{C}$ & 60 & 62 & 62 & 61 & 63 & 61 & 61 & 55 & TS \\
\hline $\mathrm{D}$ & 72 & 72 & 74 & 72 & 71 & 71 & 72 & 55 & TS \\
\hline$E$ & 71 & 72 & 72 & 72 & 65 & 73 & 71 & 55 & TS \\
\hline $\mathrm{F}$ & 68 & 70 & 72 & 68 & 69 & 70 & 69 & 55 & TS \\
\hline $\mathrm{G}$ & 71 & 72 & 71 & 71 & 71 & 68 & 70 & 55 & TS \\
\hline $\mathrm{H}$ & 63 & 64 & 64 & 64 & 65 & 60 & 63 & 55 & TS \\
\hline I & 72 & 72 & 73 & 71 & 70 & 71 & 71 & 55 & TS \\
\hline $\mathrm{J}$ & 70 & 74 & 71 & 73 & 74 & 76 & 74 & 55 & TS \\
\hline
\end{tabular}
diplotkan pada software surfer. Pada Tabel 1 berikut ini merupakan hasil dari perhitungan rumus LSM:

Tabel 1.

Nilai Kebisingan LSM

Keterangan: $\mathrm{TS}=$ Tidak Sesuai

Menurut data diatas dapat disimpulkan pada lokasi A sampai J selama 1 minggu nilai kebisingan yang dihasilkan melebihi baku mutu.

\section{Penentuan Vegetasi Sebagai Barier Buatan}

Menurut data yang telah diolah dan dihitung menggunakan rumus-rumus berdasarkan pada keputusan No.48/MENLH/11/1996, kebisingan yang dihasilkan pada sekitar lokasi rumah sakit sangat tinggi. Sehingga harus dilakukan reduksi agar disekitar rumah sakit tidak terlalu bising. Penurunan nilai kebisingan dilakukan dengan cara penanaman pohon akasia, bambu dan heliconia $s p$, pada area depan rumah sakit yaitu di sekitar tempat parkir mobil.

\section{Plotting/Pemetaan}

Data-data yang telah dihitung kemudian diplotkan ke software surfer untuk menghasilkan peta berkontur yang bertujuan untuk menentukan distribusi tingkat kebisingan pada area Rumah Sakit Islam A. Yani Surabaya. Untuk hasil pemetaan dapat ditunjukkan pada gambar-gambar berikut dibawah ini. 

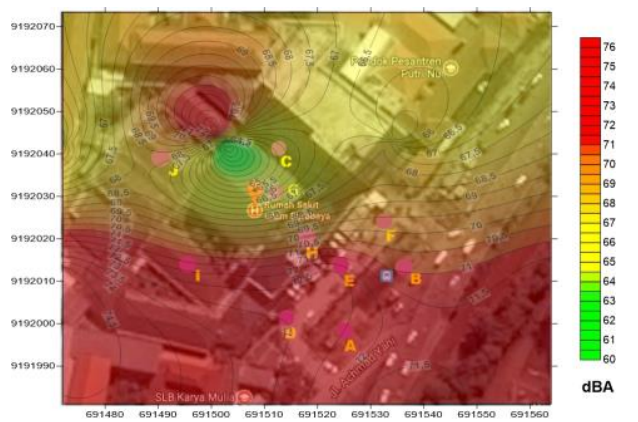

Gambar 2. Peta Kontur Kebisingan Pada Hari Senin
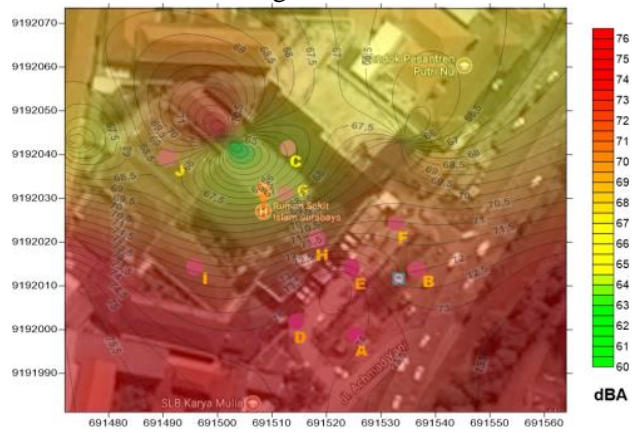

Gambar 3. Peta Kontur Kebisingan Pada Hari Selasa

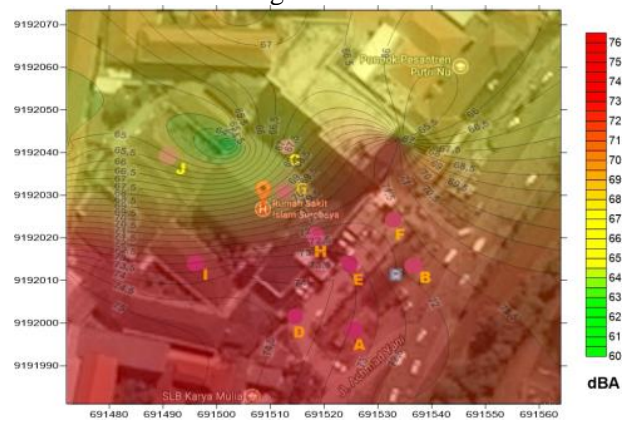

Gambar 4. Peta Kontur Kebisingan Pada Hari Rabu

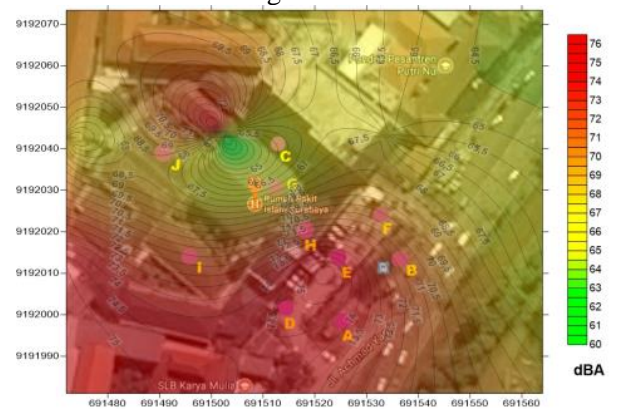

Gambar 5. Peta Kontur Kebisingan Pada Hari Kamis

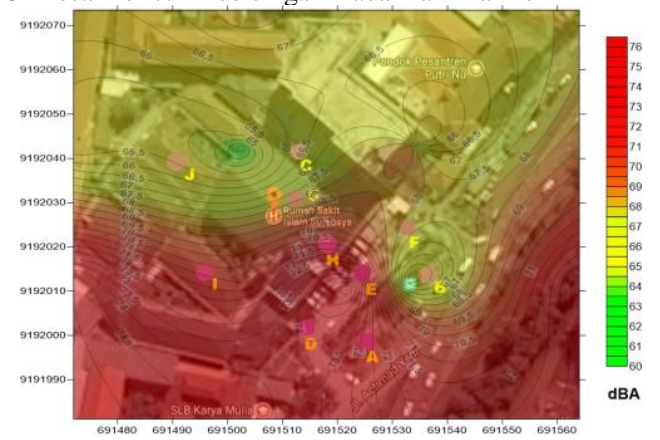

Gambar 6. Peta Kontur Kebisingan Pada Hari Jumat

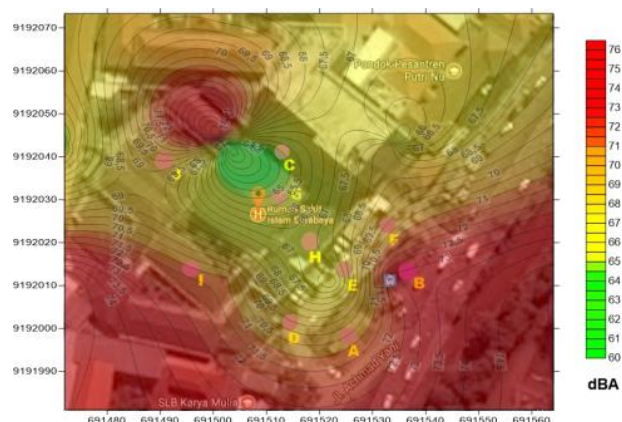

Gambar 7. Peta Kontur Kebisingan Pada Hari Sabtu

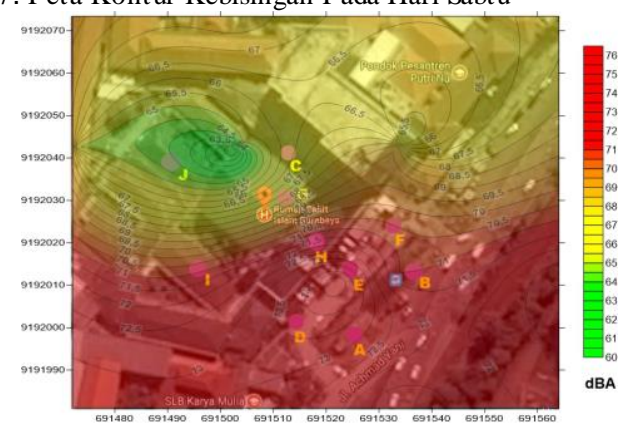

Gambar 8. Peta Kontur Kebisingan Pada Hari Minggu

Berdasarkan hasil pemetaan diatas, dapat dikatakan bahwa seluruh lokasi di Rumah Sakit mengalami kebisingan yang nilainya melebihi baku mutu. Ini disebabkan karena pada area Rumah Sakit untuk barier tambahan sangat minim jumlahnya.

\section{KESIMPULAN/RINGKASAN}

Berdasarkan hasil penelitian yang telah dilakukan di lingkungan Rumah Sakit Islam A. Yani Surabaya, dapat disimpulkan bahwa:

1. Nilai kebisingan berada pada rentang 52-92 dBA. Nilai kebisingan tertinggi terletak pada lokasi titik sampling B.

2. Menurut hasil pemetaan hampir seluruh area Rumah Sakit mengalami kebisingan yang melebihi baku mutu.

3. Penurunan kebisingan dengan menambahkan vegetasi pada area tempat parkir.

\section{UCAPAN TERIMA KASIH}

Penulis mengucapkan terima kasih kepada dosen pembimbing dan dosen penguji tugas akhir atas saran dan masukan, serta kepada direktur RSI A. Yani Surabaya terima kasih telah mengizinkan melakukan penelitian.

\section{DAFTAR PUSTAKA}

[1] D. Aprilyawan, "Pengertian Surfer," 2015 .

[2] S. Djalante, "Analisis Tingkat Kebisingan Di Jalan Raya Yang Menggunakan Alat Pemberi Isyarat Lalu Lintas (Apil) (Studi kasus: Simpang Ade Swalayan)," J. SMARTek, vol. 8, pp. 280-300, 2010.

[3] B. Griefhan, R. Scheumer, and U. Moehler, "Physiological, subjective and behavioural responses during sleep to noise from rail and road traffic," Noise Health, vol. 3, no. 9, pp. 59-71, 2000.

[4] N. Kusminingrum, "Pengaruh Tanaman Jalan Akibat Lalu Lintas Kendaraan," 1998.

[5] C. Lukita, "Analisis Kesesuaian Tingkat Kebisingan Akibat 
Traffic Noise Dengan Baku Mutu Kebisingan Di Sma Negeri 4 Surabaya," Surabaya, 2012.

[6] M. Luxson, S. Darlina, and T. Malaka, "Kebisingan Di Tempat Kerja," 2010.

[7] C. Mediastika, Akustik Bangunan Prinsip-Prinsip Dan Penerapannya Di Indonesia. Jakarta: Erlangga, 2005.

[8] E. C. Mediastika, Material Akustik Pengendali Kualitas Bunyi pada Bangunan. Yogyakarta, 2009.

[9] G. Mulyono, "Analisis Kebisingan Akibat Arus Lalu Lintas Di Rumah Sakit Pku Muhammadiyah Surakarta," in Seminar Nasional Teknik Sipil UMS, 2012.
[10] A. Mustofa, Kamus Lingkungan. Jakarta: Gelora Aksara Pramana, 2000.

[11] N. Phersiana, "Analisis Pemetaan Kebisingan Akibat Aktivitas Kerja Di Pabrik Xyz," Surabaya, 2010.

[12] F. A. N. Pinto and M. D. M. Mardones, "Noise Mapping of Densely Populated Neighborhoods," Brazil, 2007.

[13] L. Prasetyo, "Akustik," Surabaya, 2003.

[14] A. Suma'mur, Higiene Perusahaan dan Kesehatan Kerja. Jakarta: CV. Sagung Seto, 2009. 